\title{
An Empirical Study on the Relationship between the Localization of Human Resources and Operational Performance of Korean Companies in Jiangsu, China
}

\author{
Ruan Xiaowen \\ Nanjing Institute of Industry Technology, Nanjing, China
}

Keywords: Korean Companies, Localization, Human Resources, Operational Performance, Investment

\begin{abstract}
Jiangsu province has been the most popular destinationfor Korean investment. With the fast investment from Korean companies, the localization of human resources has been the hottesttopic for Korean companies because itwas supposed to have major impact on the success of Korean investment and improvement of operational performance. This paper used an empirical method to examine the relationship between the localization of human resources and the operational performance of Korean companies in Jiangsu. The results indicated the localization of human resources had great impact on the operational performance of Korean companies.
\end{abstract}

\section{Introduction}

Since the diplomatic relationship was established between China and Korea in 1992, Korea has invested nearly 60 billion USD in China. Jiangsu has been the fourth largest trade partner of Korea. There were over 5000 Korean companies invested in Jiangsu until 2016. With the fast investment from Korean companies, the localization of human resource has been the heated topic for Korean companies. This paper is to examine the relationship between the localization of human resources and operational performance of Korean companies in Jiangsu.

\section{Literature Reviews}

There are internal and external reasons why Korean companies implement the localization of human resources in China.

2.1 The internal reasons why Korean companies implement localization of human resources

2.1.1 Employing local talents to reduce cost and improving operation performance

The Localization of human resources can directly reduce the cost of employment. Cheap labor cost was regarded as the comparative advantage for the development of Chinese economy. Comparing to Korea, the labor cost of China is $60 \%-70 \%$ cheaper than Korea. Meanwhile, reducing the numbers of Korean staff in Chinese branch companies can directly reduce the cost of human resources. Implementing the localization of human resources can effectively reduce the cost of employment and improving efficiency of human resources management.1

2.1.2 Reducing cultural conflict and encouraging cultural convergence

Employing local employees who are familiar with native languages, cultures, and social norms can better represent Korean companies to communicate with consumers, government officials and other stake-holders; as a result, these local employees can reduce the cultural conflict, improving the efficiency of enterprises management and increasing the cultural convergence. 2

2.1.3 Improving the relationship with local government and improving corporate image

Employing local employees can not only reduce the language and cultural barriers but also it can increase employment and tax income for local communities which can gain the support and assistance from local government; employing local employees can create intimacy relationship with Chinese local government and establish better corporate image among Chinese customers.3 
2.2 The external reasons why Korean companies implement localization of human resources

2.2.1Geographic advantage between China and Korea

China and Korea is geographically closed which created the convenience in marine transportation and air transportation. Meanwhile, there is a strong complementarity between two countries which created the opportunities for the cooperation in economics and trade. 4

2.2.2 China can providesounded investment and development environment

China has established sounded political stability and legal system. China also established sounded infrastructure facilities and network; Chinese government issued series of favorable policies to attract foreign investment; with the implementation of China-Korea FTA which created various opportunities for Korean companies.5Meanwhile, thanking to the qualified education which provided sufficient human resources for the investment from Korean companies.

2.2.3 The largest market of China created opportunities for Korean companies

Since the implementation of reform and open to the outside, Chinas has been the second largest economic power in the world; China has been the largest market in various industries including automobiles, computers, e-business, tourism, foods, new energy, computer games, robots, clothing and others. China has been the main profit providers for many global enterprises including Volkswagen, GM, Samsung Electronics, Apple Company and etc. 6 As far as Korean industries, China has been the largest export destination including the industries of automobiles, cosmetics, tourism, electronics and chemicals. Exactly, China has been the largest overseas investment destination for Korean medium and small enterprises which reached over $22 \%$ of the total investment abroad.7

\section{Research Model}

Based on the literature review, this paper constructed the following research model which will be examined through SPSS 21.0 to test the correlation and regression among the factors.

\subsection{Research Model}

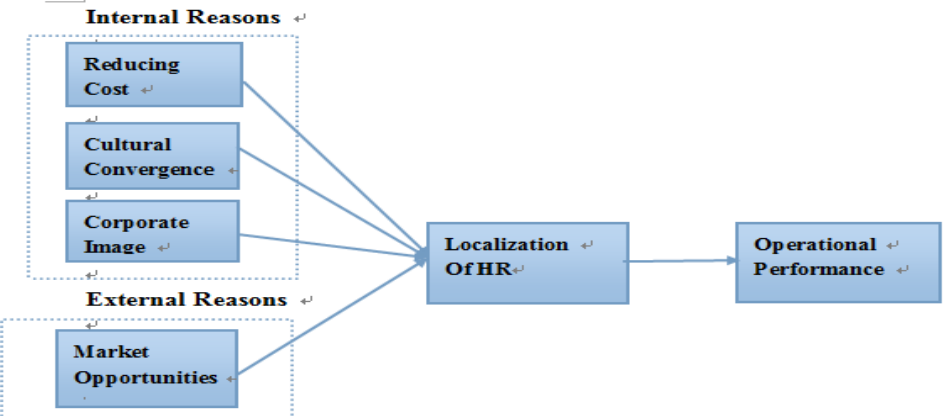

Fig. 1 Research model

\subsection{Research Hypotheses}

Based on the research model, this study constructed the following five hypotheses.

H1: The localization of HR of Korean companies is tightly related to the cost reduction.

H2: The localization of HR of Korean companies is tightly related to the cultural convergence.

H3: The localization of $\mathrm{HR}$ of Korean companies is tightly related to corporate image improvement.

H4: The localization of $\mathrm{HR}$ of Korean companies is tightly related to Chinese market opportunities.

H5: The localization of HR of Korean companies can greatly devote to the improvement of operational performance.

\subsection{Data Collection}

This study investigated over 100 Korean companies in Jiangsu province though interviews, questionnaires and online surveys. The interviews and questionnaires were composed of two parts including the general information of the localization of Korean companies in Jiangsu and the reasons why Korean companies implement the localization of human resources. 488 questionnaires 
were collected through online surveys and over 100 Korean companies' employees were interviewed.

\section{Findings and Discussions}

Based on the interviews, this study concluded the findings and constructed the following model of the localization of human resources of Korean companies in Jiangsu.

4.1 The model of localization of HR of Korean companies in Jiangsu

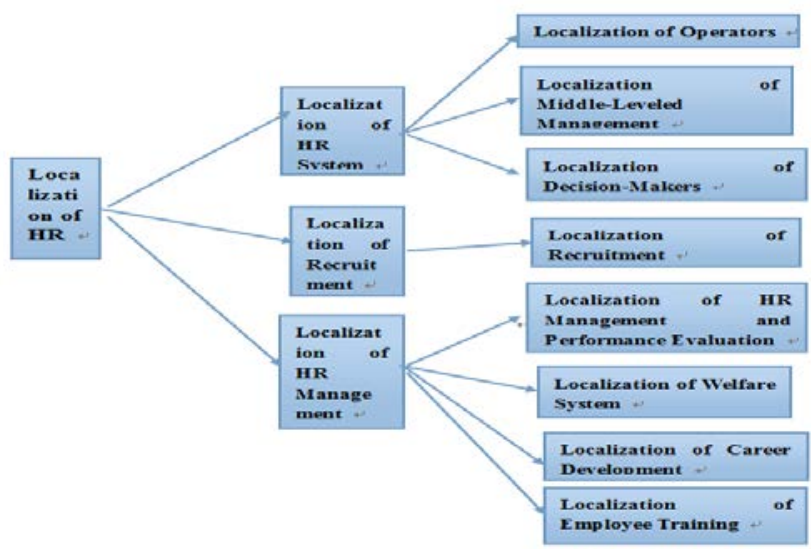

Fig. 2 The model of localization of HR of Korean companies in Jiangsu

4.2. Correlation Test

Table 1 Correlation test

\begin{tabular}{|c|c|c|}
\hline Variables & & \\
\hline \multirow{3}{*}{ Reducing cost and Localization of HR } & Pearson Correlation & $647 * *$ \\
\hline & Sig. (2-tailed) & .000 \\
\hline & $\bar{N}$ & 488 \\
\hline \multirow{3}{*}{$\begin{array}{l}\text { Cultural convergence and Localization of } \\
\text { HR }\end{array}$} & Pearson Correlation & $.292 * *$ \\
\hline & Sig. (2-tailed) & .000 \\
\hline & $\bar{N}$ & 488 \\
\hline \multirow{3}{*}{ Corporate image and Localization of HR } & Pearson Correlation & $.575^{* *}$ \\
\hline & Sig. (2-tailed) & .000 \\
\hline & $\overline{\mathrm{N}}$ & 488 \\
\hline \multirow{3}{*}{$\begin{array}{l}\text { Market opportunities and Localization of } \\
\text { HR }\end{array}$} & Pearson Correlation & $149^{* *}$ \\
\hline & Sig. (2-tailed) & .001 \\
\hline & $\bar{N}$ & 488 \\
\hline \multirow{3}{*}{$\begin{array}{l}\text { Localization of HR and Operational } \\
\text { performance }\end{array}$} & Pearson Correlation & $.755^{* *}$ \\
\hline & Sig. (2-tailed) & .000 \\
\hline & $\overline{\mathrm{N}}$ & 488 \\
\hline
\end{tabular}

**. Correlation is significant at the 0.01 level (2-tailed)

The above results indicated that all of the factors are positively related each other which is significant at 0.01 level.

4.3 Model Summary 
Table 2 Model summary

\begin{tabular}{|c|c|c|c|c|}
\hline \multicolumn{5}{|l|}{ Model Summary } \\
\hline Variable & $\beta$ & $\mathrm{R} 2$ & Adjusted R2 & $\begin{array}{l}\text { Std. Error of the } \\
\text { Estimate }\end{array}$ \\
\hline $\begin{array}{l}\text { Internal reasons, external reasons } \\
\text { and Localization of HR }\end{array}$ & $.926 a$ & .857 & .856 & .37973599 \\
\hline $\begin{array}{l}\text { Localization of HR and Operational } \\
\text { performance }\end{array}$ & $.755 a$ & .570 & .569 & .65676415 \\
\hline
\end{tabular}

The above table indicated that there is a positive relationship between Internal reasons and external reasons. Results indicated that $85.6 \%$ of the variances were explained by Localization of HR (R2=.857,, $\mathrm{B}=.926$, p-value < 0.01), Therefore, H1,H2 H3 and H4 are all supported. It also indicated that Localization of HR and operational performance is positively related and results indicated that $57 \%$ of the variances were explained by Operational Performance $(\mathrm{R} 2=.57, \Omega=.755$, p-value < 0.01). Therefore H5 is supported.

\subsection{Coefficients}

Table 3 Coefficients

\begin{tabular}{|c|c|c|c|c|c|}
\hline \multirow[t]{2}{*}{ Model } & \multicolumn{2}{|c|}{$\begin{array}{l}\text { Unstandardized } \\
\text { Coefficients }\end{array}$} & \multirow{2}{*}{ 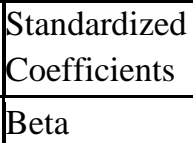 } & $\mathrm{t}$ & \multirow[t]{2}{*}{ Sig. } \\
\hline & $\mathrm{B}$ & Std. Error & & & \\
\hline 1 (Constant) & $1.001 \mathrm{E}-013$ & .017 & & .000 & 1.000 \\
\hline Reducing cost and Localization of HR & 647 & .017 & .647 & 37.621 & .000 \\
\hline Cultural convergence and Localization of HR & .292 & .017 & .292 & 16.976 & .000 \\
\hline Corporate image and Localization of HR & .575 & .017 & .575 & 33.399 & .000 \\
\hline Market opportunities and Localization of HR & .149 & .017 & .149 & 8.673 & .000 \\
\hline $\begin{array}{l}\text { Localization of HR and Operational } \\
\text { Performance }\end{array}$ & .755 & .030 & .755 & 25.358 & .000 \\
\hline
\end{tabular}

The above table indicated that the Coefficients between Reducing cost and Localization of HR is .647 at sig $=.000<.05$. The Coefficients between Cultural convergence and Localization of HR is .292 at sig $=.000<0.05$. The Coefficients between Corporate image and Localization of HR is .575 at sig $=.000<.05$. The Correlation between Market opportunities and Localization of HR is .149 at sig $=.090>.05$. The coefficients between Localization of HR and Operational performance is .755 at significant $=.000<.05$.

\section{Conclusion}

Based on the findings, it can see that there is amazing progress in localization of human resources among Korean companies in Jiangsu. The results indicated that localization of human resources can greatly reduce the cost in human resources and enterprises operation. The localization of human resources can greatly devote to the cultural convergence and it can reduce the cultural conflict. The localization of human resources can devote to the image development of Korean companies. The localization of human resources can benefit Korean companies from the economic development of China and Chinese market. Finally, the localization of human resources can devote to a better operational performance of Korean companies. 


\section{References}

[1]. X. D. Li,A study on the localization of human resources of global logistics enterprises,Journal ofComputerization of Management, 14(2011)64-65. .

[2]. M. Hu.A discussion on the problems of localization of human resources of foreign enterprises. Journal of Chinese Business and World, 2(2008)89-90.

[3]. URL:http://www.preservearticles.comtion.htm(04. 08. 2015.)

[4]. S. R. Kim,. The changes of China foreign policy and the investment from Korea after China entering WTO. Journal of Issues of International Trade, 3(2008)34-39.

[5]. S. Yang,An analyze of Korean investment in China. Journal of National Economy, 2(2006)61-63.

[6]. L. Ye,Openness and convergence of Chinese civilization. Journal of Beijing University,2 (2014)88-92.

[7]. C. M. Wu,An analyze of the investment strategy of global enterprises in China. Journal of Theory World,5 ( 2006) 15-20 